\title{
Pengaruh Pelatihan, Kompetensi, Kompensasi, dan Motivasi Kerja terhadap Kinerja Polisi Lalu Lintas Polresta Banjarmasin
}

\author{
Andi Tri Hidayat ${ }^{1}$, Titien Agustina ${ }^{2}$ \\ Pascasarjana Universitas Merdeka Malang ${ }^{1,}$ Sekolah Tinggi Ilmu Manajemen Indonesia (STIMI) Banjarmsin ${ }^{2}$ \\ Alamat Jl. Terus Dieng No. 62, Malang, Jawa Timur ${ }^{1}$ \\ Alamat Jl. Kuripan No. 26 Banjarmasin, Kalimantan Selatan ${ }^{2}$ \\ anditrihidayat@gmail.com \\ titienagustina9@gmail.com
}

\begin{abstract}
Traffic Police Polresta Banjarmasin improves the public services. The public services improvement depend on The Performance. The performance is influenced by traning, competency, compensation, and work motivation. To analyzing and to know the influence of those variables to the performance need the research in police lalu lintas Polresta Banjarmasin. Quantitative method is used in the research. The population is all members of the police. They are 90 persons. Technique of sampling is census. This research sample 63 person. The data collection technique is questioner. Data is analyzed by linier regression analysis. The results of this research shows that traning, competency, compensation, and work motivation have influence significantly to the performance partially. Traning, competency, compensation, and work motivation are need to improve because these variables have influence significantly to the performance improvemet.
\end{abstract}

\begin{abstract}
Abstrak - Polresta lalu lintas Banjarmasin meningkatkan pelayanan publik. Peningkatan layanan publik tergantung pada Kinerja. Kinerja dipengaruhi oleh traning, kompetensi, kompensasi, dan motivasi kerja. Untuk menganalisis dan mengetahui pengaruh variabel-variabel tersebut terhadap kinerja perlu penelitian di Polri lalu lintas Polresta Banjarmasin. Metode kuantitatif digunakan dalam penelitian ini. Populasi adalah semua anggota polisi. Mereka adalah 90 orang. Teknik pengambilan sampel adalah sensus. Sampel penelitian ini 63 orang. Teknik pengumpulan data adalah kuesioner. Data dianalisis dengan analisis regresi linier. Hasil penelitian ini menunjukkan bahwa traning, kompetensi, kompensasi, dan motivasi kerja berpengaruh signifikan terhadap kinerja secara parsial. Traning, kompetensi, kompensasi, dan motivasi kerja perlu ditingkatkan karena variabel-variabel ini memiliki pengaruh signifikan terhadap peningkatan kinerja.
\end{abstract}

Kata kunci : Kinerja, pelatihan, kompetensi, kompensasi, dan motivasi kerja

\section{PENDAHULUAN}

Perubahan sosial yang berjalan seiring dengan perkembangan globalisasi telah membawa pengaruh terhadap perubahan paradigma masyarakat. Menyadari dan memahami sepenuhnya keberadaan Polantas saat ini, diperlukan strategi ke depan yang sesuai dengan perubahan lingkungan strategik yang dihadapi Polantas. Perubahan Paradigma Polantas seiring dengan perubahan paradigma Polri yang merupakan refleksi dan tuntutan terhadap peningkatan peran dan tugas Polantas yang semakin kompleks di tengah - tengah masyarakat. Tuntutan akan Polantas yang Profesional dan Proporsional yang bercirikan Perlindungan, Pengayoman, Pelayanan kepada masyarakat, Penegakan Demokrasi dan Hak Asasi Manusia dalam rangka kepastian hukum dan terwujudnya kamtibcar lantas menuntut reposisi atas kedudukan serta pemulihan fungsi dan peranannya.

Polantas berupaya semaksimal mungkin menjalankan tugas sebagai pelindung, pengayom dan pelayan masyarakat serta penegakan hukum lalu lintas, pengkajian masalah lalu lintas, registrasi dan identifikasi kendaraan bermotor dan pengemudi, demi tercapainya keamanan, ketertiban dan kelancaran lalu lintas. Namun kasus pencurian motor masih terjadi di kalangan masyarakat. Pencurian ini terjadi di Banjarmasin. Pada tahun 2018 terjadi kasus pencurian motor sebanyak 64 kali.

Tabel 1.1 Jumlah Inventaris Ranmor Dinas Fungsi Lantas

Bulan April 2018

\begin{tabular}{clccc}
\hline \multirow{2}{*}{ NO } & JENIS KENDARAAN & $\begin{array}{c}\text { KELRESTA } \\
\text { BANJARMASIN }\end{array}$ & & \\
\cline { 3 - 4 } & & 3 & 4 & 5 \\
\hline A & \multicolumn{1}{c}{2} & - & - & \\
\hline A & RANMOR R 2 & 2 & 2 & \\
& RX KING & 8 & 8 & \\
& THUNDER 250 CC & - & - & \\
& THUNDER 125 CC & 8 & 8 & \\
B & SCORPION & - & - & \\
& RX - Z & 4 & 4 & \\
& YAMAHA 900 CC & 1 & 1 & \\
C & TIGER & - & - & \\
& SMASH & 23 & 23 & \\
& R2 100 - 500 CC & 3 & 3 & \\
D & RANMOR R4 & 1 & 1 & \\
& KIJANG & 4 & 4 &
\end{tabular}




\begin{tabular}{|c|c|c|c|c|}
\hline \multirow[b]{2}{*}{ NO } & \multirow[b]{2}{*}{ JENIS KENDARAAN } & KESATUAN & \multirow[b]{2}{*}{ JUMLAH } & \multirow[b]{2}{*}{ KET } \\
\hline & & $\begin{array}{c}\text { POLRESTA } \\
\text { BANJARMASIN }\end{array}$ & & \\
\hline 1 & 2 & 3 & 4 & 5 \\
\hline \multirow{8}{*}{ E. } & YHUNDAI & & & \\
\hline & MITSUBISHI L200 & - & - & \\
\hline & SUZUKI JIMNY & - & - & \\
\hline & PATHER & 1 & 1 & \\
\hline & PICK UP & 1 & 1 & \\
\hline & MINIBUS & 5 & 5 & \\
\hline & LAND CRUISER & - & - & \\
\hline & $\begin{array}{l}\text { TRUCK DEREK / } \\
\text { BIS }\end{array}$ & 3 & 3 & \\
\hline \multicolumn{2}{|c|}{ JUMLAH TOTAL } & 64 & 64 & \\
\hline
\end{tabular}

Sumber : Satlantas Polresta Banjarmasin, 2018

Upaya mengatasi kasus-kasus seperti ini memerlukan kinerja polisi lalu lintas yang baik. Kinerja yang baik menjadi syarat mutlak yang harus dimiliki oleh semua personil polisi termasuk polisi lalu lintas. Kinerja polisi lalu lintas merupakan gambaran mengenai tingkatan pencapaian pelaksanaan suatu program kegiatan atau kebijakan untuk mewujudkan sasaran, tujuan, visi dan misi organisasi yang dituangkan dalam perencanaan strategis polisi lalu lintas di jalan. Kinerja diukur menggunakan kriteria atau standar yang ditetapkan organisasi atau suatu lembaga kepolisian.

Hasil survey awal di bagian lalu lintas Polresta Banjarmasin memberikan gambaran kinerja anggota polisi yang bertugas di Polresta Banjarmasin. Hasil survei 20 orang mengenai kinerja polisi lalu lintas Polresta Banjarmasin ditunjukkan melalui tabel sebabai berikut.

Tabel 1.2

Kinerja Polisi Lalu Lintas Polresta Banjarmasin

\begin{tabular}{clllcll}
\hline \multirow{2}{*}{ No. Aspek Penilaian } & \multicolumn{5}{c}{ Kategori } \\
\cline { 2 - 6 } & $\begin{array}{c}\text { Sangat } \\
\text { Rendah }\end{array}$ & Rendah & Sedang & Tinggi & $\begin{array}{l}\text { Sangat } \\
\text { Tinggi }\end{array}$ \\
\hline 1 & Prestasi Kerja & - & - & $10 \%$ & $80 \%$ & $10 \%$ \\
2 & Tanggung jawab & - & - & - & $80 \%$ & $20 \%$ \\
3 & Ketataan & - & - & - & $80 \%$ & $20 \%$ \\
4 & Kejujuran & - & - & - & $100 \%$ & - \\
5 & Kerja sama & - & - & - & $90 \%$ & $10 \%$ \\
\hline
\end{tabular}

Sumber : Data diolah tahun 2018

Tabel di atas menunjukkan bahwa kinerja polisi khususnya anggota satuan lalu lintas Polresta Banjarmasin perlu ditingkatkan, khususnya pencapaian prestasi kerja. Pada tabel di atas terdapat $10 \%$ mencapai kriteria sedang. Idealnya kinerja yang dicapai untuk semua aspek mencapai kategori tinggi. Di antara faktor-faktor itu, faktor yang dapat diintervensi melalui pelatihan adalah faktor ability (kemampuan yang dapat dikembangkan). Faktorfaktor lain di luar jangkauan pelatihan (Notoatmodjo, 2009: 21). Jadi, kemampuan karyawan atau pekerja dipengaruhi oleh pelatihan.
Variabel lain yang perlu dipehatikan dalam organisasi adalah kompensasi. Karyawan maupun pekerja diberikan penghargaan finansial dan non finansial oleh organisasi berdasarkan tugas yang dikerjaan dan hasil pekerjaan yang telah dilakukan. Kompensasi bisa berbentuk gaji, pemberian hari libur, dan bonus. Kompensasi diberikan sesuai dengan kinerja pegawai. Kinerja yang dicapai sesuai dengan kompensasi yang diberikan organisasi.

Kinerja pegawai ditentukan oleh kompetensi yang dimiliki. Kompetensi dan kinerja merupakan kunci pencapaian kinerja organisasi yang optimal. Organisasi mebutuhkan SDM yang berkompeten dan professional dalam mencapai visi serta mampu melaksanakan misi organisasi.Kompetensi dan kinerja SDM menyangkut kewenangan setiap pegawai untuk melaksanakan tugas atau mengambil keputusan sesuai dengan perannya dalam organisasi, yang sesuai dengan keahlian, pengetahuan dan kemampuan yang dimilikinya.Kompetensi dan kinerja SDM harus mampu mendukung pelaksanaan strategi organisasi agar tercapai dengan optimal. Dengan kata lain kompetensi yang dimiliki oleh pegawai harus mampu mendukung sistem kinerja yang ada dalam organisasi dalam menghadapi perubahan lingkungan persaingan dan bisnis yang semakin kompetitif. Kompetensi yang tinggi akan mempengaruhi kinerja yang ditampilkan oelh pegawai. Kinerja pegawai yang tinggi akan sangat terpengaruh terhadap kinerja organisasi secara keseluruhan (Priansa, 2014: 252).

Selain itu faktor motivasi juga penting ditingkatkan dalam organisasi. Karyawan harus selalu dimotivasi agar kinerja yang dihasilkan meningkat. Sebab kejenuhan bekerja sering terjadi di tempat kerja. Apabila gejala ini terjadi pada diri karyawan, dapat dilihat ciri-cirinya seperti absensi (ketidak hadiran) meningkat, disiplin merosot, produktivitas menurun, labour turn over (tingkat keluar masuk karyawan masuk) makin tinggi, ada tuntutan karyawan yang tidak henti-hentinya, sampai pada gejala pemogokan (Alma, 2008: 202).

Motivasi berhubungan langsung dengan kinerja karyawan. Motivasi dapat dipastikan mempengaruhi kinerja, walaupun bukan satu-satunya faktor yang membentuk kinerja (Wibowo, 2011: 389). Kebutuhan adanya kekurangan fisiologis atau psikologis yang menimbulkan perilaku. Teori motivasi berdasarkan hirarki kebutuhan dikemukakan Abraham Maslow menyatakan bahwa kebutuhan manusia berjenjang dari psysiological, safety, social, dan self actualization (Wibowo, 2011: 391). 
Peneliti akan mengkaji pengaruh pelatihan, kompetensi, kompensasi, dan motivasi dengan kinerja Polisi Lalu Lintas Polresta Banjarmasin.

\section{KAJIAN PUSTAKA}

Kinerja adalah kesuksesan seseorang dalam melaksanakan suatu pekerjaan yang dilaksanakannya. Kinerja adalah apa yang dapat dikerjakan oleh seseorang sesuai dengan tugas dan fungsinya. Dari batasan-batasan yang ada dapat dirumuskan bahwa kinerja (performance) adalah hasil kerja yang dapat ditampilkan atau penampilan kerja seorang karyawan. Dengan demikian kinerja seorang karyawan dapat diukur dari hasil kerja, hasil tugas, atau hasil kegiatan dalam ukuran waktu tertentu (Notoatmodjo, 2009:124).

Pelatihan adalah suatu proses yang akan menghasilkan suatu perubahan perilaku terhadap karyawan atau pegawai. Secara kongkrit perubahan itu berupa peningkatan kemampuan karyawan atau pegawai dalam mengerjakan tugas di tempat kerja (Notoatmodjo, 2009: 18). Wibowo (2009: 442) mendefinisikan bahwa pelatihan adalah segenap usaha agar mendapatkan sumber daya manusia yang memiliki pengetahuan dan keterampilan tertentu sehingga mereka dapat menggunakannya dalam pekerjaan.

Kompetensi memiiki elemen yaitu terdiri dari pengetahuan (knowledge), keterampilan (skill) dan dan perilaku (personal attributes).Secara umum, kompetensi adalah tingkat keterampilan, pengetahuan dan tingkah laku yang dimiliki oleh seorang individu dalam melaksanakan tugas yang dibebankan kepadanya dalam organisasi.

Kompensasi adalah segala sesuatu yang diterima oleh karyawan sebagai balas jasa untuk kerja atau pengabdian mereka. Dalam suatu organisasi masalah kompensasi merupakan hal yang sangat kompleks, namun paling penting bagi karyawan maupun organisasi itu sendiri. Pemberian kompensasi kepada karyawan harus mempunyai dasar yang logis dan rasional. Namun demikian faktor-faktor emosional dan perikemanusiaan tidak boleh diabaikan (Notoadmodjo, 2009: 142).

Terry (Sedarmayanti, 2009: 233) mendefisikan bahwa motivasi adalah keinginan yang terdapat pada seseorang atau individu yang merangsangnya untuk melakukan tindakan. Motivasi adalah suatu kekuatan yang dihasilkan dari keinginan seseorang untuk memuaskan kebutuhannya, misal; rasa lapar, haus, dan dahaga. Motivasi berarti kekuatan kecendrungan seseorang atau individu melibatkan diri dalam kegiatan yang mengarah kepada pekerjaan tertentu. Pengertian motivasi menurut Terry adalah keinginan yang terdapat pada diri seseorang individu yang mendorongnya untuk melakukan perbuatan-perbuatan (perilaku) tertentu (Notoatmodjo, 2009:114). Stooner mendefinisikan bahwa motivasi adalah sesuatu hal yang menyebabkan dan yang medukung tindakan atau perilaku seseorang (Notoatmodjo, 2009: 114). Flippo (Notoatmodjo, 2009:114) merumuskan bahwa motivasi adalah suatu arahan pegawai dalam suatu organisasi agar mau bekerja sama dalam mencapai keinginan para pegawai dalam rangka pencapaian keberhasilan organisasi.

\section{METODE PENELITIAN}

Penelitian ini menganalisis pengaruh pelatihan, kompensasi, dan motivasi terhadap kinerja anggota Polisi Lalu Lintas Polresta Banjarmasin. Selain itu penelitian ini juga menganalisis gambaran pelatihan, kompensasi, dan kinerja Polisi Lalu Lintas Polresta Banjarmasin. Pelatihan, kompensasi, dan motivasi kerja, serta kinerja merupakan objek kajian manajemen sumber daya manusia.

Variabel ini terdiri atas dua macam variabel, yaitu variabel dependent variable dan independent variable. Dependent variable ini adalah kinerja pegawai $(\mathrm{Y})$. Independent variable adalah pelatihan (X1), kompetensi (X2), kompensasi (X3), dan motivasi kerja (X4).

Penelitian ini menggunakan skala pengukuran Likert. Skala likert digunakan untuk mengukur sikap, pendapat, dan persepsi seseorang atau kelompok tentang fenomena sosial. Dengan skala ini, fenomena yang ditetapkan secara spesifi oleh peneliti disebut variabel penelitian. Variabel yang diukur dijabarkan menjadi indikator variabel. Kemudian indikator dijadikan sebagai acuan untuk menyusun pertanyaan instrumen yang dapat berupa pernyataan atau pertanyaan (Sugiyono, 2008: 107).

\section{Hasil Uji Asumsi}

\section{HASIL DAN PEMBAHASAN}

Uji asumsi dilakukan sebelum membahas hasil analisis regresi. Uji asumsi dilakukan dengan uji normalitas, heterokedastisitas, dan multikolinieritas.

\section{Hasil Uji Normalitas}

Normalitas data dengan mudah diketahi dengan menggunakan P-P Plot. Jika titik-titik mengikuti garis lurus pada P-P Plot maka data berdistribusi normal. Titik-titik pada P-P Plot di atas mengikuti garis lurus sehingga data penelitian ini berdesitribusi normal. 
Gambar 1 Hasil Uji Normalitas

mal P-P Plot of Regression Standardized Residual

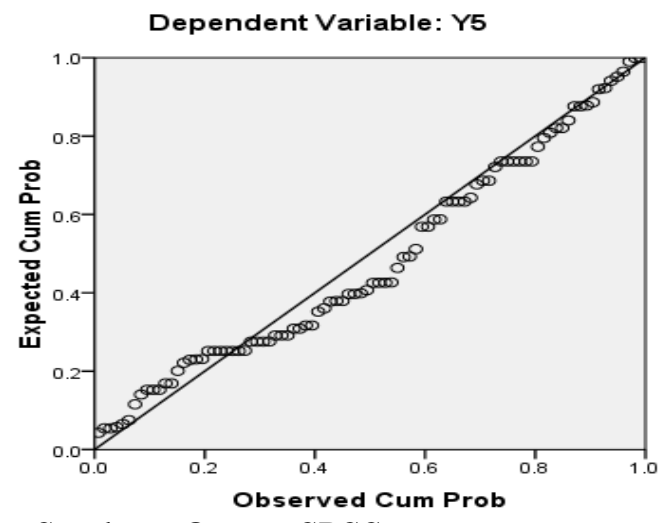

Sumber : Output SPSS

2. Hasil Uji Heteroskedastisitas

Uji heterokedastisitas dilakukan dengan mudah dan praktis dilakukan dengan melihat diagram pancar Parcial Regression Plot. Titik-titik tidak membentuk pola tertentu dalam diagram pancar maka data tidak mengalami heterokedastisitas. Diagram pancar berikut ini menujukkan data pelatihan penelitian ini tidak mengalami heterokedastisitas.

Gambar Hasil Uji Heteroskedastisitas

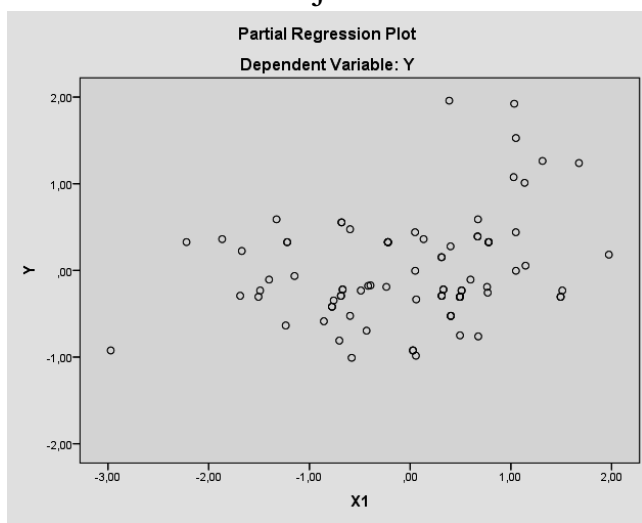

Sumber : Output SPSS

3. Hasil Uji Multikolinieritas

Multkolinieritas diuji dengan menggunakan nilai tolerance dan VIF. Jika nilai tolerance $\geq 1$ dan nilai VIF $\leq 10$ maka data penelitian tidak mengalami multikolinieritas. Tabel berikut ini hasil berisi tolerance dan VIF hasil analisis regresi penelitian ini.

Tabel 1 Tolerance dan VIF

\begin{tabular}{clcc}
\hline No & \multicolumn{1}{c}{ Variabel } & Tolerance & VIF \\
\hline 1. & Pelatihan (X1) & 0,13 & 7,9 \\
2. & Kompetensi (X2) & 0,14 & 7,3 \\
3. & Kompensasi (X3) & 0,1 & 10
\end{tabular}

4. Motivasi Kerja (X4)

0,14

7,1

Sumber : Data yang diolah

Data pelatihan, kompetensi, kompensasi, dan motivasi kerja tidak mengalami multikolinieritas. Data di atas membuktikan bahwa nilai tolerance pelatihan, kompetensi, kompensasi, dan motivasi kerja $\geq 1$ dan VIF $\leq 10$.

\section{Hasil Analisis Regresi}

Hasil analisis regresi penelitian ini disajikan dengan tabel koefisien determinan, uji $\mathrm{F}$, dan uji $\mathrm{t}$ atau disebut dengan koefisien regresi.

Tabel 2 Koefisien Determinan

\begin{tabular}{lrrr}
\hline R & R Square & \multicolumn{1}{c}{$\begin{array}{c}\text { Adjusted R } \\
\text { Square }\end{array}$} & $\begin{array}{c}\text { Std. Error of the } \\
\text { Estimate }\end{array}$ \\
\hline 0.986 & 0.971 & 0.970 & 0.57791 \\
\hline
\end{tabular}

Sumber ; Data yang diolah

Persentase pengaruh pelatihan, kompetensi, kompensasi, dan motivasi kerja dapat dipredeksi dengan menggunakan koefisien determinan. Pada tabel koefisien determinan menunjukkan nilai $\mathrm{R}$ 0,986 . Nilai $R \quad 0,986$ dikuadratkan menjadi 0,970 . Nilai $R$ square $\left(R^{2}\right) 0,970 \times 100 \%=97 \%$. Ini menunjukkan bahwa pelatihan, kompetensi, kompensasi, dan motivasi memberian pengaruh sebesar 97\% terhadap kinerja polisi lalu lintas Polresta Banjarmasin.

Tabel 3 Hasil Uji F

\begin{tabular}{|c|c|c|c|}
\hline df & Mean Square & $\mathrm{F}$ & Sig. \\
\hline 4 & 241.625 & 723.482 & $0.000^{\mathrm{a}}$ \\
\hline 85 & 0.334 & & \\
\hline 89 & & & \\
\hline
\end{tabular}

Sumber : data yang diolah

Model penelitian ini perlu diuji dengan uji $\mathrm{F}$. Jika $\mathrm{F}$ hitung $>\mathrm{F}$ tabel dengan signifikan $<0,05$, maka model penelitian ini diputuskan sudah tepat. Pada tabel F di atas, diketahui nilai $\mathrm{F}$ hitung mencapai 723.482 dengan signifikan 0,000 . Nilai $F$ tabel pada tabel $\mathrm{F}$ dengan df 4 dan df 85 meunjukkan angka 2,53. Jadi $F$ hitung sebesar $723.482>F$ tabel 2,53 dengan signifikan $<0,05$. Dengan demikian model penelitian ini sudah tepat atau layak.

\section{Tabel 3 Koefisien Regresi}

\begin{tabular}{ccccccc}
\hline \multirow{2}{*}{$\begin{array}{c}\text { Pengaruh Variabel } \\
\text { independen terhadap } \\
\text { variabel dependen }\end{array}$} & \multicolumn{2}{c}{$\begin{array}{c}\text { Unstandardized } \\
\text { Coefficients }\end{array}$} & t & Sig. \\
\cline { 2 - 3 } (Constanta) & 1,203 & Std. Error & & & \\
\hline
\end{tabular}




\begin{tabular}{rccrr}
\hline $\mathrm{X} 1 * \mathrm{Y}$ & 0,167 & 0,066 & 2.548 & 0,013 \\
\hline $\mathrm{X} 2 * \mathrm{Y}$ & $-0,556$ & 0,058 & -9.618 & 0,000 \\
\hline $\mathrm{X} 3 * \mathrm{Y}$ & 0,806 & 0,070 & 11.573 & 0,000 \\
\hline $\mathrm{X} 4 * \mathrm{Y}$ & 0,625 & 0,047 & 13.248 & 0,000 \\
\hline \multicolumn{5}{r}{ Sumber $;$ data yang diolah } \\
\end{tabular}

Hipotesis penelitian ini dapat diuji dengan menggunakan koefisien regresi. Hipotesis penelitian ini berisi pengaruh pelatihan, kompetensi, kompensasi, dan motivasikerja terhadap kinerja polisi lalu lintas Polresta Banjarmasin secara parsial. Kriteria yang dipakai untuk menguji hipotesis ini adalah nilai signifikan $<0,05$. Jika sginifikansi $>0,05$ maka terdapat pengaruh yang signifikan.

Signifikansi pengaruh pelatihan terhadap terhadap kinerja $\left(\mathrm{X} 1^{*} \mathrm{Y}\right)$ polisi lalu lintas Polresta Banjarmasin 0,013. Signifikansi pengaruh pelatihan terhadap kinerja polisi ini $<0,05$. Ini berarti hipotesis yang menyebutkan pelatihan berpengaruh signifikan terhadap kinerja polisi lalu lintas Polresta Banjarmasin diterima.

Signifikansi pengaruh kompetensi terhadap terhadap kinerja $(\mathrm{X} 2 * \mathrm{Y})$ polisi lalu lintas Polresta Banjarmasin 0,000. Signifikansi pengaruh kompetensi terhadap kinerja polisi ini $<0,05$. Ini berarti hipotesis yang menyebutkan kompetensi berpengaruh signifikan terhadap kinerja polisi lalu lintas Polresta Banjarmasin diterima.

Signifikansi pengaruh kompensasi terhadap terhadap kinerja $(\mathrm{X} 3 * \mathrm{Y})$ polisi lalu lintas Polresta Banjarmasin 0,000. Signifikansi pengaruh kompetensi terhadap kinerja polisi ini $<0,05$. Ini berarti hipotesis yang menyebutkan kompensasi berpengaruh signifikan terhadap kinerja polisi lalu lintas Polresta Banjarmasin diterima.

Signifikansi pengaruh kompensasi terhadap terhadap kinerja $(\mathrm{X} 4 * \mathrm{Y})$ polisi lalu lintas Polresta Banjarmasin 0,000. Signifikansi pengaruh motivasi kerja terhadap kinerja polisi ini $<0,05$. Ini berarti hipotesis yang menyebutkan motivasi kerja berpengaruh signifikan terhadap kinerja polisi lalu lintas Polresta Banjarmasin diterima.

Pembahasan

1. Pengaruh Pelatihan terhadap Kinerja

Hasil pelatihan mempengaruhi kinerja polisi lalu lintas Polresta Banjarmasin. Pelatihan yang dilakukan sesuai dengan bidang pekerjaan polisi lalu lintas memberikan pengaruh terhadap peningkatan kinerja polisi lalu lintas Polresta Banjarmasin. Dengan pelatihan seperti ini kinerja polisi ini meningkat yang dominan peningkatannya pada bekerja sesuai standar mutu. Notoatmodjo (2009:

21) menyatakan pelatihan adalah faktor ability (kemampuan yang dapat dikembangkan). Faktorfaktor lain di luar jangkauan pelatihan. Kemampuan karyawan atau pekerja dipengaruhi oleh pelatihan.

2. Pengaruh Kompetensi terhadap Kinerja

Kompetensi yang maksimal dengan pengatahuan yang memadai memberikan pengaruh signifikan pada peningkatan kinerja polisi lalu lintas Polresta Banjarmasin. Pengetahuan yang baik akan memberikan kontribusi pada kinerja yang baik dengan hasil kerja sesuai dengan standar mutu yang ditetapkan.

3. Pengaruh Kompensasi terhadap Kinerja

Kompensasi yang baik dengan pemberian tunjangan yang dapat memenuhi kebutuhan memberikan pengaruh signifikan terhadap kinerja dengan hasil kerja sesuai standar mutu. Polisi diberikan penghargaan finansial dan non finansial oleh organisasi berdasarkan tugas yang dikerjaan dan hasil pekerjaan yang telah dilakukan. Kompensasi bisa berbentuk gaji, pemberian hari libur, dan bonus. Kompensasi diberikan sesuai dengan kinerja pegawai. Kinerja yang dicapai sesuai dengan kompensasi yang diberikan organisasi. Kompensasi merupakan sistem yang mampu menjamin kepuasan para anggota organisasi yang pada gilirannya memungkinkan organisasi memperoleh, memelihara, dan mempekerjakan sejumlah orang yang dengan yang memiliki sikap dan perilaku positif bekerja dengan produktif untuk kepentingan organisasi (Siagian, 2008: 253).

\section{Pengaruh Motivasi terhadap Kinerja}

Polisi lalu lintas Polresta Banjarmasin termotivasi bekerja dengan baik untuk memenuhi kebutuhan memberikan pengaruh terhadap kinerja polisi dalam hal pencapaian hasil kerja sesuai standar mutu. Motivasi juga penting ditingkatkan dalam organisasi. Karyawan harus selalu dimotivasi agar kinerja yang dihasilkan meningkat. Sebab kejenuhan bekerja sering terjadi di tempat kerja. Apabila gejala ini terjadi pada diri karyawan, dapat dilihat ciricirinya seperti absensi (ketidak hadiran) meningkat, disiplin merosot, produktivitas menurun, labour turn over (tingkat keluar masuk karyawan masuk) makin tinggi, ada tuntutan karyawan yang tidak hentihentinya, sampai pada gejala pemogokan (Alma, 2008: 202). 


\section{KESIMPULAN DAN SARAN}

Kesimpulan

Hasil analisis data dan pembasan penelitian ini membuktikan pengaruh pelatihan, kompetensi, kompensasi, dan motivasi kerja terhadap kinerja polisi.

1. Pelatihan berpengaruh signifikan terhadap kinerja Polisi Lalu Lintas Polresta Banjarmasin.

2. Kompetensi berpengaruh signifikansi terhadap kinerja Polisi Lalu Lintas Polresta Banjarmasin.

3. Kompensasi berpengaruh signifikan terhadap kinerja Polisi Lalu Lintas Polresta Banjarmasin.

4. Motivasi kerja berpengaruh signifikan terhadap kinerja Polisi Lalu Lintas Polresta Banjarmasin. Saran

Berdasarkan kesimpulan di atas, dapat diberikan saran kepada personil dan pimpinan satlantas Polresta Banjarmasin.

1. Personil polisi lalu lintas Polresta Banjarmasin perlu meningkatkan kompetensi dan motivasi kerja untuk meningkatkan kinerja.

2. Pimpinan satlantas Polresta Banjarmasin perlu meningkatkan pelaksanaan pelatihan dan meningkatkan pemberian kompenssasi untuk meningkatkan kompetensi dan kinerja personil polisi lalu lintas Polresta Banjarmasin.

\section{REFERENSI}

[1] Alma, Buchari.2008. Pengantar Bisnis. Bandung: Alfabeta.

[2] Anggreani. D. S. 2015. engaruh Kompensasi dan Motivasi Kerja Terhadap Kinerja Karyawan: Studi pada Rumah Makan di Kota Banjarmasin. Tesis. Program Studi Magister Manajemen. Universitas Merdeka Malang.

[3] Arikunto, Suharsimi. 2010. Prosedur Penelitian. Jakarta: Rineka Cipta.

[4] Dewi dkk (2013). Pengaruh Motivasi, Kompensasi Melalui Kepuasan Kerja terhadap Kinerja Karyawan Studi Kasus Karyawan PT. Pelindo III Semarang. (Online) Diakses dari Vivinqueen@yahoo.com tanggal 10 September 2014.
[5] Edison, Emron, Yohni Anwar,dan Imas Komariyah. 2017. Manajemen Sumber Daya Manusia. Bandung: Alfabeta.

[6] Ghozali, Imam. 2016. Aplikasi Analisis Multivariate dengan Program IMB Statistik 23. Semarang : Badan Penerbit Universitas Diponegoro.

[7] Gomes, Faustino Cardoso, 2003, Manajemen Sumber Daya Manusia. Yogyakarta: Andi Offset.

[8] Misbahuddin dan Iqbal Hasan. 2013. Analisis Data Penelitian dengan Statistik. Jakarta: Bmi Aksara.

[9] Notoatmodjo, Soekidjo. 2009. Pengembangan Sumber Daya Manusia. Jakarta: PT Rineka Cipta.

[10] Nugroho, B. A. 2005. Strategik Jitu Memilih Metode Statistik Penelitian dengan SPSS. Yogyakarta: ANDI.

[11] Robbin, Stephen P. 2008. Perilaku Organisasi. Jakarta : Salemba Empat.

[12] Samsuddin, Sadli.2006. Manajemene Sumber Daya Manusia, Bandung: CV Pustaka Setia.

[13] Schuler Randall S, Dowling, Peter J Smart, John P \& Huber, Vandral, 1992. Human Resource Management. Australia: Anatarmon-wsw, Harper Educational Publisher.

[14] Sedarmayanti. 2009. Manajemen Sumber daya Manusia. Bandung: PT Refika Aditama.

[15] Sugiyono. 2008. Metode Penelitian Administrasi. Bandung: Alfabeta.

[16] Sunyoto, Danang. 2012. Teori. Kuisioner, dan Analisis Data Sumber Daya Manusia. Yogyakarta : CAPS.

[17] Triton. 2009. Mengelola Sumber Daya Manusia. Yogyakarta: Oryza.

[18] Triyono, Ayon. 2012. Paradigma Baru Manajemen Sumber Daya Manusia. Yogyakarta: Oryza.

[19] Umar, Hasan. 2010. Desain Penelitian SDM dan Perilaku Karyawan. Jakarta: PT RajaGrafindo. 